\title{
Implementasi Modul GPS Ublox 6M dalam Rancang Bangun Sistem Keamanan Motor Berbasis Internet of Things
}

\author{
Yosef Doly Wibowo $^{1}$, Yuliarman Saragih, ${ }^{2}$, Rahmat Hidayat ${ }^{3}$ \\ Program Studi Teknik Elektro Universitas Singaperbangsa Karawang \\ J1. H.S Ronggowaluyo Telukjambe Timur - Karawang 41361 \\ ${ }^{1}$ ydolywibowo@gmail. com \\ ${ }^{2}$ yuliarmanestaff.unsika.ac.id \\ ${ }^{3}$ rahmat.hidayatestaff.unsika.ac.id
}

Intisari - Produsen sepeda motor berhasil memasang alarm sebagai indikator sistem keamanan standar pada sepeda motor. Alarm tersebut mampu mengeluarkan suara melalui speaker yang terpasang pada kendaraan. Usaha penerapan alat tersebut ternyata tidak efektif karena alarm dapat dimatikan oleh oknum pencuri. Perkembangan teknologi saat ini diiringi dengan perkembangan teknologi smartphone. Setiap orang pasti memiliki smartphone. Perangkat keamanan sepeda motor dapat dirancang melalui pemanfaatan smartphone. Smartphone yang terhubung dengan GPS melalui jaringan seluler dapat digunakan untuk memonitoring letak sepeda motor melalui aplikasi Blynk dan memastikan kondisi sepeda motor dalam keadaan baik. Selain meningkatkan nilai fungsi smartphone, alat ini juga meningkatkan rasa aman bagi pemilik kendaraan. GPS Modul Ublox 6M berhasil dibuktikan dalam penelitian ini dengan menghasilkan keakuratan dan monitoring kendaraan sebesar $95 \%$ aman.

Kata Kunci-Global Positionig System (GPS), Blynk, Internet Of Think (IOT)

Abstract - Motorcycle manufacturers have succeeded installed an alarm as an indicator of a standard safety system on a motorcycle. The alarm is capable for sounding a sound through installing speaker on the vehicle. Efforts to implement this tool turned out to be ineffective, because the alarm could be turned off by the thieves. Current technological developments are accompanied by developments in smartphone technology. Everyone does have a smartphone. Motorcycle safety devices can be designed by utilizing a smartphone. A smartphone connected to a GPS via a cellular network can be used to monitor the location of the motorcycle through the Blynk application and to ensure that the motorbike is in good condition. Besides increasing the value of smartphone functions. This tool also increases the sense of security for vehicle owners. The Ublox 6M GPS Module was successfully proven in this study by producing accuracy and successfully monitoring around $\mathbf{9 5 \%}$ safe vehicles.

Keywords-Global Positionig System (GPS), Bylnk, Internet Of Think (IOT) 


\section{PENDAHULUAN}

Dunia teknologi saat ini sudah berkembang sangat pesat. Penggunaan teknologi membuat suatu pekerjaan menjadi lebih dinamis dan efisien, menuntut banyak industri untuk melakukan peningkatan kualitas dan kuantitas pada hasil produknya serta sesuai dengan peningkatan permintaan pasar. Dalam hal ini perusahaan industri sepeda motor bisa memperbaiki sistem dan proses produksi dengan menerapkan teknologi yang berkembang saat ini. Akibat dari permasalahan keterbatasan manusia membuat seseorang ceroboh pada saat memarkirkan kendaraannya sehingga muncul permasalahan lupa mengunci stang kendaraan, atau lupa untuk mencabut kunci kontak kendaraannya hingga pencurian sepeda motorpun tidak terhindari.

Ada beberapa metode untuk melakukan pencarian barang hilang khususnya kendaraan. Salah satunya metode konvensional adalah dengan melakukan pencarian secara manual, yaitu dengan menghubungi pihak tukang parkir, satpam atau kepolisian atau bahkan mencari secara langsung. Ternyata masih banyak masyarakat yang belum memanfaatkan teknologi yang sudah berkembang saat ini untuk mengamankan dan melacak kendaraan yang sudah dicuri. Metode yang terbaru ini adalah dengan menggunakan teknologi GPS yang akan memberitahu lokasi kendaraan kepada si pemilik.

Berbagai cara ditempuh salah satunya menggunakan alat-alat pengaman kendaraan. Dalam kasus kehilangan atau kerusakan, asuransi merupakan solusi yang efektif. Namun sistem pembayaran yang dilakukan secara rutin membuat pemilik kendaraan harus berpikir kembali apakah biaya yang dikeluarkan sesuai dengan jaminan yang diberikan. Alat-alat pengaman kendaraan seperti kunci ganda atau alarm pencurian merupakan alat yang berfungsi hanya untuk menghambat proses pencurian. Selain itu asuransi dan alat-alat pengaman kendaraan seperti diatas tidak dapat membuat kendaraan yang hilang atau dicuri dapat ditemukan.

Pemanfaatan teknologi GPS pada keamanan kendaraan bermotor merupakan alternatif solusi yang menarik, ini dapat menjadi solusi sebenarnya dari masalah keamanan kendaraan. Dengan menggunakan GPS, pemilik kendaraan dapat melacak lokasi kendaraannya dimanapun kendaraanya berada. Tidak ada lokasi yang aman bagi pencuri untuk menyembunyikan kendaraan curiannya karena jangkauan GPS dapat menjangkau seluruh permukaan bumi. [9]

Berdasarkan permasalahan di atas dapat dirancang sebuah sistem pelacakan lokasi sepeda motor berbasis Internet of Thing (IOT). Dengan menghubungkannya ke Global Positioning System (GPS) Modul Ublox Neo $6 \mathrm{~m}$, maka lokasi sepeda motor dapat dipantau melalui smartphone. Sistem seperti ini sebenarnya sudah pernah dibuat, yang umumnya menguankan arduino sebagai basisnya. Perlu dibuat pembeda antara sistem yang pernah dibuat dengan sistem yang akan dibuat, karena itu digunakanlah Internet of Things (IOT) sebagai basis. Dengan demikian smartphone dapat digunakan selain untuk alat komunikasi juga sebagai sistem pelacakan lokasi sepeda motor. [11]

\section{TINJAUAN PUSTAKA}

\section{A. Smartphopne}

Ukuran Smartphone adalah telepon seluler dengan mikroprosesor, memori, layar dan modem bawaan. Smartphone merupakan ponsel multimedia yang menggambungkan fungsiolitas PC dan handset sehingga menghasilkan gadget yang mewah, di mana terdapat pesan teks, kamera, pemutar musik, video, game, akses email, tv digital, search engine, pengelola informasi pribadi, fitur GPS dan jasa telepon internet (Williams \& Sawyer .2011). Untuk mendapatkan software yang cocok pada perangkat ponsel pintar yang mencakup sistem operasi middle-ware dan yang berfungsi sebagai pendukung multimedia, integrasi browser dan dapat mendukung perangkat seperti GPS, Sensor Accelerometer, jaringan 3G hingga HSPA. Perangkat yang mendukung untuk fungsi yang cangih dapat ditemukan di smartphone pintar seperti Android, iPhone [9]. 


\section{B. Global Positioning System (GPS)}

GPS adalah sistem satelit navigasi dan pemantauan posisi yang dimiliki dan dikelola oleh Ameika Serikat. Sistem ini didesain untuk memberikan posisi dan kecepatan tiga-dimensi serta informasi mengenai waktu, secara kontinu di seluruh dunia tanpa bergantumg waktu dan cuaca, bagi banyak orang secara simultan. Saat ini GPS sudah banyak digunakan orang di seluruh dunia dalam berbagai bidang aplikasi yang menuntut informasi tentang posisi, kecepatan, percepatan ataupun waktu yang teliti. GPS dapat memberikan informasi posisi dengan ketelitian bervariasi dari beberapa milimeter (orde nol) sampai dengan puluhan meter. Tampak atas dari modul GPS Ublox Neo 6MV2 dapat dilihat pada gambar 2 [9].

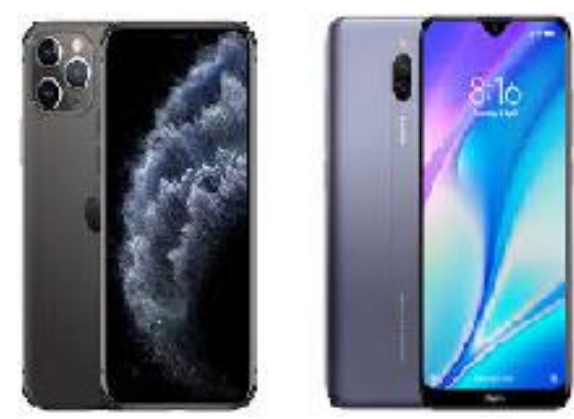

Gbr. 1 Smartphone

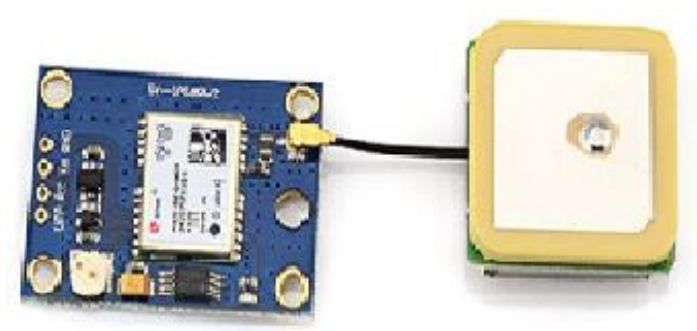

Gbr. 2 Modul GPS Neo Ublox 6M

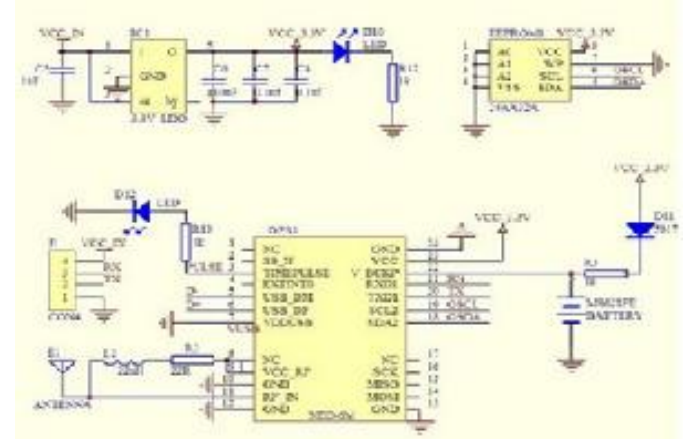

Gbr. 3 Skematik Modul GPS Ublox Neo 6M
Konsep dasar pada GPS untuk mendapatkan data koordinat meliputi beberapa hal yang sangat penting, berikut ini akan dijelaskan beberapa konsep dasar GPS.

\section{1) Tinjauan Kemampuan GPS}

Beberapa kemampuan GPS antara lain dapat memeberikan informasi tentang posisi secara cepat dan akurat dimana saja di bumi tanpa tergantung cuaca. Hal yang perlu dicatat bahwa GPS adalah satu-satunya sistem navigasi ataupun sistem penentuan posisi dalam beberapa abad ini yang memiliki kemampuan handal seperti ini. Ketelitian dari GPS dapat mencapai beberapa $\mathrm{mm}$ untuk ketelitian posisinya, beberapa $\mathrm{cm} / \mathrm{s}$ untuk ketelitian kecepatannya dan beberapa nanodetik untuk ketelitian waktunya. Ketelitian posisi yang diperoleh akan tergantung pada beberapa faktor yaitu metode penentuan posisi,geometri satelite,tingkat ketelitian data, dan metode pengolahan datanya.

\section{2) Segmen Penyusun Sistem GPS}

Secara umum ada tiga segmen dalam sistem GPS yaitu segmen sistem satelit dan segmen pengguna. Satelit GPS dapat dianalogikan sebagai stasiun radio angkasa, yang diperlengkapi dengan antenaantena untuk mengirim dan menerima sinyal-sinyal gelombang. Sinyalsinyal ini selanjutnya diterima oleh receiver GPS di/dekat permukaan bumi, dan digunakan untuk menentukan informasi posisi, kecepatan, maupun waktu. Selain itu sateli GPS juga dilengkapi dengan peralatan untuk mengontrol attidute satelit. Satelit-satelit GPS dapat dibagi atas beberapa generasi yaitu: blok I, blok II, blok IIA, blok IIR dan blok IIF. Hingga april 1999 ada 8 satelit blok II, 18 satelit blok IIA dan 1 satelit blok IIR yang beroperasi.

Secara umum segmen sistem kontrol berfungsi mengontrol dan memantau operasional satelit dan memastikan bahwa satelit berfungsi sabagaimana mestinya. Segmen pengguna terdiri dari para pengguna satelit GPS dimanapun berada. Dalam hal ini alat penerima sinyal GPS (GPS receiver) diperlukan untuk digunakan dalam penentuan posisi, kecepatan dan waktu. Komponen 
utama digunakan dari suatu receiver GPS secara umum adalah antenna dengan preamplifier, bagian RF dengan pengidentifikasi sinyal dan pemroses sinyal, pemroses mikro untuk pengontrolan receiver, data sampling dan pemroses data (solusi navigasi), osilator presisi, catu daya, unit perintah dan tampilan.

\section{3) Prinsip penentuan posisi pengan GPS}

Prinsip penentuan posisi dengan GPS yaitu menggunakan metode reseksi jarak, dimana pengukuran jarak dilakukan secara simultan ke beberapa satelit yang telah diketahui koordinatnya. Pada pengukuran GPS, setiap epoknya memiliki empat parameter yang ditentukan yaitu 3 parameter koordinat $\mathrm{X}, \mathrm{Y}, \mathrm{Z}$ atau L,B,h dan satu parameter kesalahan waktu akibat ketidaksinkronan jam osilator di satelit dengan jam di receiver GPS. Oleh karena diperlukan minimal pengukuran jarak ke empat satelit.

\section{4) Sinyal Bias pada GPS}

GPS memancarkan dua sinyal yaitu frekuensi LI (1575.42 MHz,) dan (1227.60 $\mathrm{MHz}$ ). Sinyal L1 dimodulasikan dengan dua sinyal pseudo random yaitu kode $\mathrm{P}$ (Protected) dan kode C/A (coarse/acquisition). Sinyal L2 hanya membawa kode P. Setiap satelit mentransmisikan kode yang unik sehingga penerima (receiver GPS) dapat mengidentifikasi sinyal dari setiap satelit. Pada saat fitur "Anti- Spoofing" diaktifkan, maka kode $\mathrm{P}$ akan dienkripsi dan selanjutnya dikenal sebagai kode $\mathrm{P}(\mathrm{Y})$ atau kode $\mathrm{Y}$.

Ketika sinyal melalui lapisan atmosfer, maka sinyal tersebut akan terganggu oleh konten dari atmosfer tersebut. Besarnya gangguan di sebut bias. Bias sinyal yang ada utamanya terdiri dari 2 macam yaitu bias ionosfer dan bias troposfer.

\section{5) Metode penentuan posisi dengan GPS}

Metode penentuan posisi dengan GPS pertama-tama terbagi dua, yaitu metode absolut, dan metode diferensial. Masingmasing metode kemudian dapat dilakukan dengan ara real time dan atau post-processing. Apabila obyek yang ditentukan posisinya diam maka metodenya disebut statik.
Sebaliknya apabila obyek yang ditentukan posisinya bergerak, maka metodenya disebut kinematic.

Selanjutnya lebih detail lagi kita akan menemukan metode-metode seperti SPP, DPSG, RTK, Survey GPS, rapid static, pseduo kinematic, dan stop and go, serta masih ada beberapa metode ada beberapa metode lainnya.

6) Ketelitian posisi yang diperoleh dari sistem GPS

Untuk aplikasi sipil, GPS memberikan nilai ketelitian posisi dalam spectrum yang cukup luas, mulai dari meter sampai dengan millimeter. Sebelum mei 2000(SA on) ketelitian posisi GPS metode absolut dengandata psedorange mencapai 30-100 meter. Kemudian setelah SA off ketelitian membaik menjadi 3-6 meter. Sementara itu teknik DGPS memberikan ketelitian 1-2 meter, dan teknik RTK memberikan ketelitian 1-5 sentimeter. Untuk posisi dengan ketelitian milimeter diberikan oleh teknik survey GPS dengan peralatan GPS tipe geodetic dual frekuensi dan strategi pengolahan data tertentu.

\section{7) Kekurangan pada teknologi GPS}

Pada sistem GPS pasti memiliki kekurangan yang akan mempengaruhi ketelitian hasil posisi yang diperoleh dengan mengandalkan setidaknya tiga satelit ini tidak selamanya akurat. Alat GPS ini juga dipengaruhi oleh posisi satelit yang berubah dan adanya proses sinyal yang ditunda. Kecepatan sinyal GPS ini juga seringkali berubah karena dipengaruhi oleh kondisi atmosfer yang ada. Selain itu, sinyal GPS juga mudah berinteferensi dengan gelombang elektromagnetik lainnya (Arfianto Nogroho, 2012). GPS adalah sebuah alat kecil yang menerima sinyal dari beberapa satelit. GPS ini adalah salah satu bagian dari sistem dan GPS ini akan dipasangkan ke dalam kendaraan yang akan menagkap dan merespon untuk mengikuti informasi antara lain seperti lokasi terkini dari kendaraan.

Sistem GPS tracker dikembangkan untuk mengirimkan data koordinat lokasi kendaraan via Smartphone. Selama kendaraan bergerak, alat ini secara cepat memberikan parameter 
lokasi dengan SMS. Dengan menggunakan teknologi GPS dan GSM memungkinkan untuk dapat mengikuti jejak kendaraan dan mendukung pemberitahuan untuk dapat mengikuti jejak kendaraan dan mendukung pemberitahuan informasi perjalanan terkini.

\section{Google Maps}

Untuk mengakses google maps dari PC dekstop atau laptop, bisa diakses ke alamat http://maps.google.com melalui Firefox, Chrome, atau browser lainya. Selain browser di PC atau laptop, aplikasi Google Maps juga bisa diakses melalui perangkat mobile dengan sistem OS. Untuk mengaksesnya, pengguna smartphone cukup membuka aplikasi Google Maps yang sudah diunduh lewat penyedia jasa aplikasi di perangkat smartphone, lalu tampilan peta akan ditampilkan oleh google maps [9].

\section{1) Mengenal google maps}

Google maps mapping service adalah sebuah online tool yang memberikan user berbagai fitur-fitur map seperti tampilan street maps, arahan kemudian point-to-point, dan jalur-jalur untuk mencari lokasi yang belum pernah didatangi, sekolah, universitas dan masih banyak lagi. Degan tambahan street map dan terrain view, satellite atau aerial views dapat memberikan tampilan yang mudah dipahami user dan dapat diakses siapa saja melalui online connection

Google Maps masih merupakan layanan pemetaan yang paling kuat yang pernah ada. Baik Anda menggunakan Google Maps dalam browser pada desktop Anda, atau sebuah aplikasi pada ponsel Anda. Google Maps dikemas dengan fitur-fitur yang sangat berguna, namun beberapa dari mereka sedikit tersembunyi. Salah satunya adalah kemampuan aplikasi Google Maps yang memungkinkan Anda untuk menemukan arah di komputer dan kemudian dengan cepat melihatnya di ponsel smartphone.

2) Mengenal fitur yang digunakan pada Google Maps

Berikut ini fitur - fitur dan tips cara menggunakan Google Maps agar dapat mencapai tempat tujuan lebih cepat :
- Fitur Mencari Koordinat GPS

Untuk menentukan koordinat lokasi yang tepat, fitur ini dapat menampilkan data Latitude and Longitude dari GPS. Dapat memasukan sebuah alamat untuk melihat koordinat garis lintang dan garis bajunya, melihat garis lintang dan garis bujurnya, melihat garis lintang dan garis bujur setiap titik pada peta, atau memasukan koordinat dan melihatnya pada peta Google.

\section{- Fitur Navigasi}

Fitur navigasi dirancang untuk berkendara, lebih khusus untuk untuk memandu seseorang ke satu alamat yang dituju atau lokasi koordinat yang akan dicari. Dilengkapi dengan voice, perintah suara dan jalur alternatif. Lebih mirip sebagai alat navigasi yang biasa dipakai di kendaraan dan memerlukan GPS aktif untuk akurasi. Dengan fitur navigasi pada aplikasi Google maps akan mempercepat proses pencarian lokasi yang belum diketahui.

\section{Blynk}

Blynk merupakan platform baru yang memungkinkan anda untuk dengan cepat membangun interface untuk mengendalikan dan menantau proyek hardware dari IOS dan perangkat Android. Blynk adalah IOT (Internet of Things) yang dirancang untuk membuat remote control dan data sensor membaca dari perangkat ESP8266 ataupun Arduino dengan sangat cepat dan mudah. Blynk bukan hanya sebagai "cloud IOT", tetapi blynk juga merupakan solusi end to end yang menghemat waktu dan sumber daya ketika membangun sebuah aplikasi yang berarti bagi produk dan jasa terkoneksi [12].

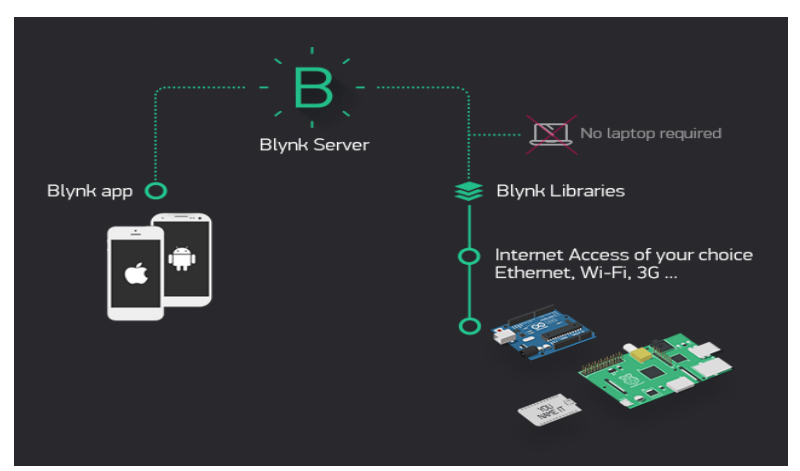

Gbr. 4 Blynk 


\section{METODE PENELITIAN}

\section{A. Perancangan Sistem}

Merancang dan mendesain dalam bentuk hardware dan software, serta memperoleh hasil yang diinginkan yang tidak melenceng dari tujuan awal, maka dibuatlah diagram blok system pelacakan lokasi sepeda motor yang sederhana, seperti gambar 5 .

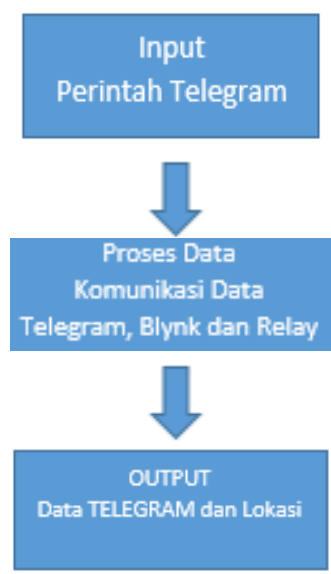

Gbr. 5 Gambaran Blok Diagram Blok Sistem

Dari blok diagram tersebut dapat dijelasakan bagaimana sistem yang akan dibuat memerlukan input data pesan yang digunakan untuk mengirim perintah pada alat melalui Telegram. Selain itu juga diperlukan perangkat GPS Modul Ublox Neo 6m untuk mencari atau mendeteksi titik koordinat sebuah tempat sebelum kemudian diproses dan ditampilkan melalui aplikasi Blynk. Setelah semua input terpenuhi, maka diperlukan sistem pengendali yang dapat diatur untuk mengeksekusi perintah. Pada sistem pelacakan sepeda motor, diperlukan sebuah relai yang bisa digunakan untuk mematikan mesin sepeda motor. Kemudian titik koordinat yang dihasilkan oleh perangkat GPS Modul Ublox Neo $6 \mathrm{~m}$ dapat dikirimkan kesebuah smartphone dan dapat langsung ditampilkan melalui aplikasi Blynk. Berdasarkan pada Gambar 3.1, maka dibuatlah sebuah blok diagram sistem pelacakan lokasi sepeda motor seperti gambar 6 .

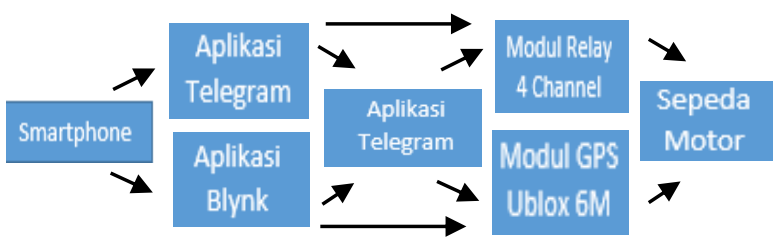

Gbr. 6 Rancangan Blok Diagram
Berdasarkan diagram blok di atas dapat dijelaskan bahwa smartphone digunakan untuk mengirim perintah melalui Aplikasi Telegram yang akan melakukan eksekusi relai. GPS Modul Ublox Neo 6m akan mencari koordinat lokasi yang kemudian dibaca oleh Aplikasi Bylnk. dapat dilihat bahwa gambar yang menunjukkan sebuah sistem keamanan sepeda motor berbasis IoT. Rancangan menggunakan beberapa beberapa komponen utama, yaitu: Smartphone, Aplikasi Telegram, Aplikasi Blynk, NodeMCU ESP 8266, GPS U-Blox 6 M, dan Relay 4 Channel.

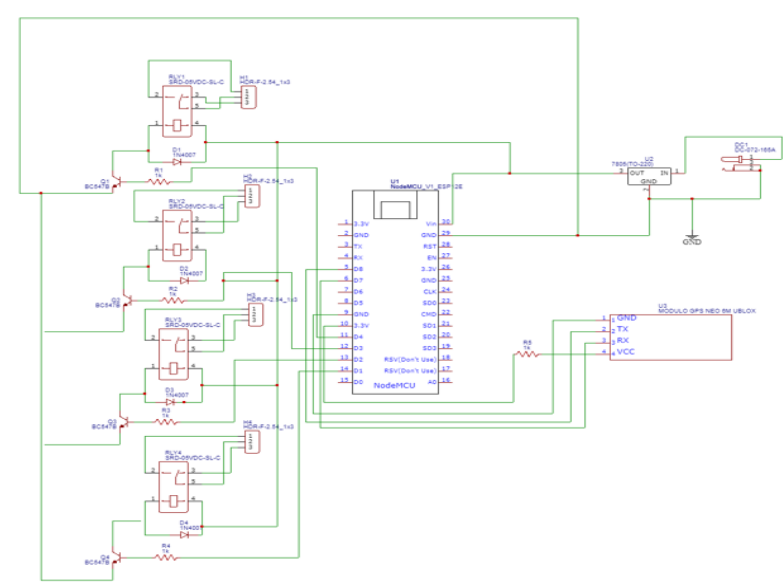

Gbr. 7 Skematik Alat

\section{B. Perancangan Software}

Perancangan Program dibuat menggunakan Software Arduino IDE. Pada line program yang terdapat pada gambar diatas, modul GPS pada perlu dideklarasikan terlebih dahulu agar NodeMCU dapat membacanya melalui pin-pin IO yang telah di deklarasikan. Arduino IDE telah menyediakan library GPS untuk NodeMCU sehingga mempermudah dalam proses pemrogramannya muncul sebagai indicator. Seperti varibel kecepatan dideklarasikan pada pin virtual 3, variabel satelit pada pin virtual 4, dan variabel arah pada pin virtual 5 .

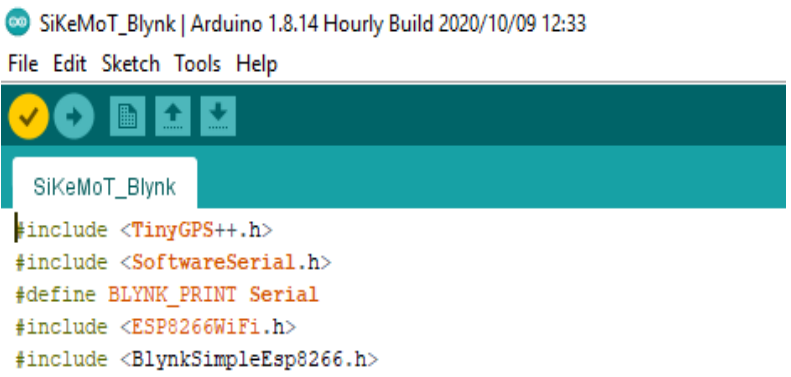

Gbr . 8 Deklarasi Fungsi GPS 
Rancangan program "Pelacakan Lokasi Sepeda Motor Menggunakan Modul GPS Ublox 6M" dalam bentuk flowchart ditunjukam pada gambar 9 .

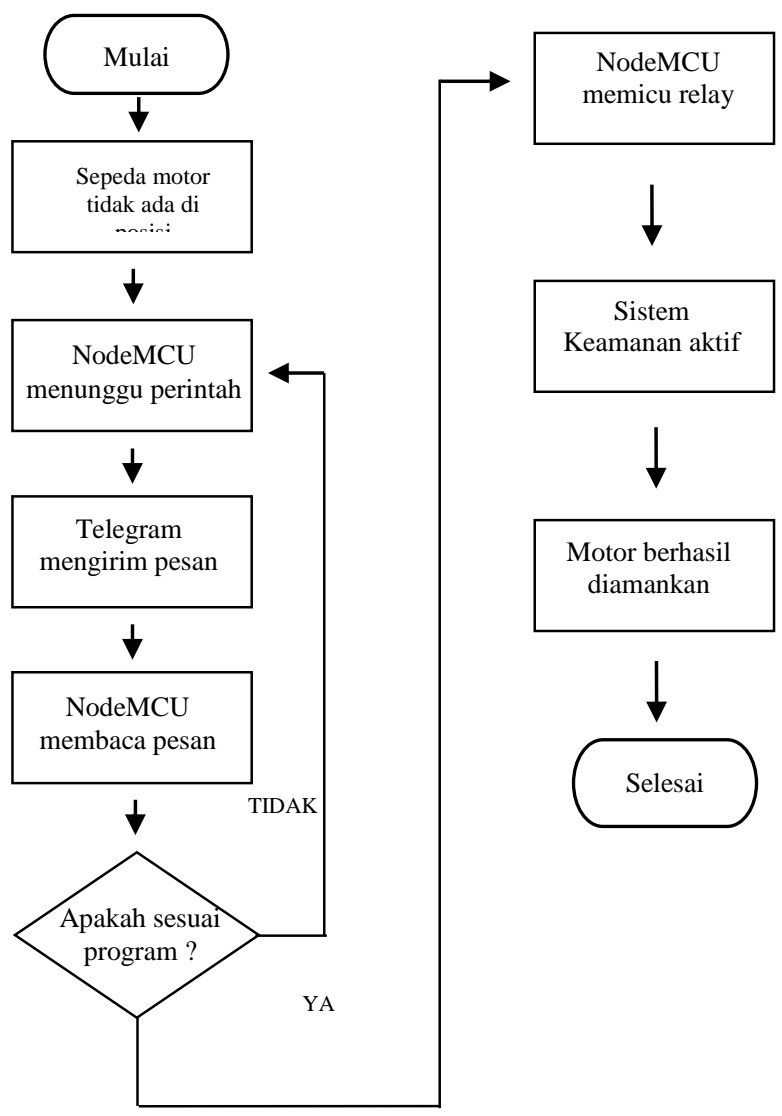

Gbr. 9 Flowchart

\section{HASIL DAN PEMBAHASAN}

Setelah dilakukan pembuatan alat "Pelacakan Lokasi Sepeda Motor Menggunakan Modul GPS Ublox 6M" seperti Gambar, maka selanjutnya dilakukan pengujian.

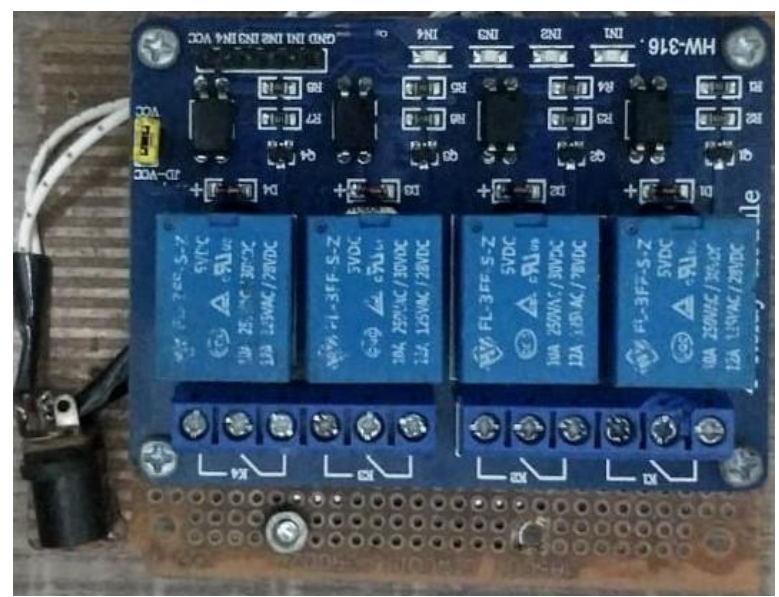

(Tampak Atas)

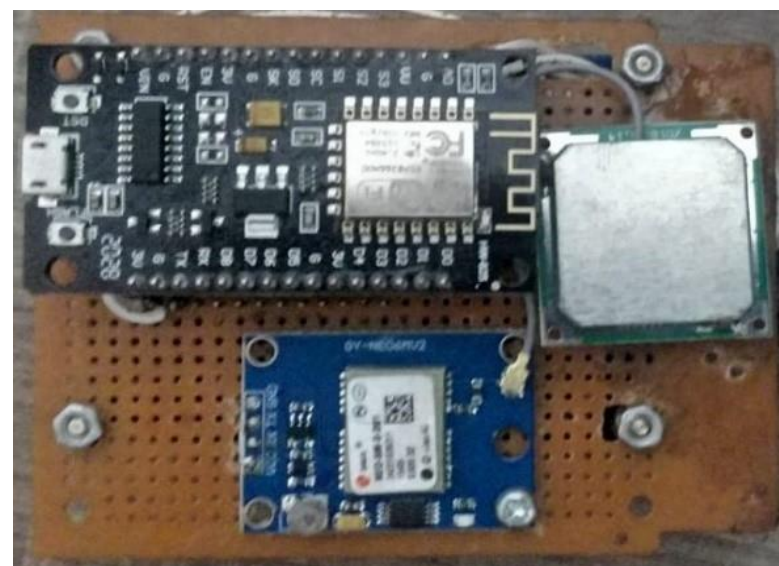

(Tampak Bawah)

Gbr. 10 Rangkaian Aktual Alat

\section{A. Pengujian}

Pengujian dilakukan untuk melihat hasil kinerja alat yang dibuat apakah sudah sesuai dengan yang diharapkan. Pengujian kali ini dilakukan dibeberapa tempat sehingga memunculkan hasil respon yang berbeda-beda kemudian dapat dianalisas dan disimpulkan melalui rata-rata hasil yang didapat.

\section{1) Pengukuran Waktu Respon GPS}

Pengujian waktu pada di GPS untuk mengamati berapa lama waktu yang dibutuhkan alat agar terhubung ke satelit

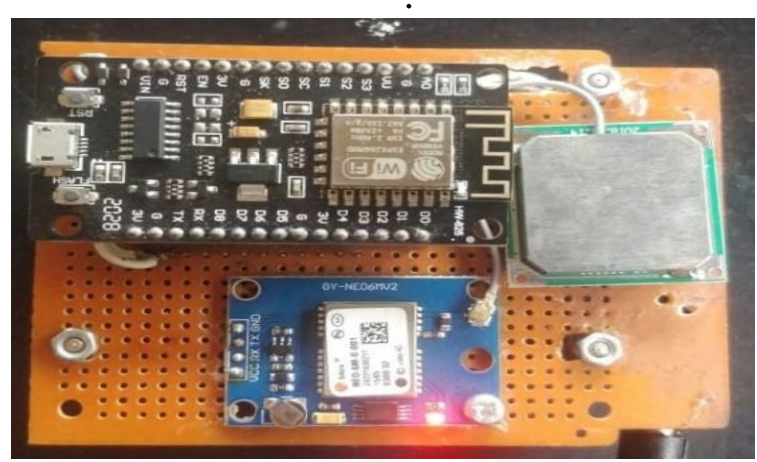

Gbr. 11 rangkaian GPS

Modul GPS memiliki LED yang akan berkedip sebagai indicator telah mendapatkan sinyal dari satelit. Pada situasi normal dengan kondisi sinyal GPS baik, Alat membutuhkan waktu sekitar 5 detik setelah dinyalakan untuk terhubung ke. Namun pada beberapa kondisi seperti berada pada daerah yang tertutup dan memiliki kualitas sinyal yang buruk GPS memerlukan waktu yang cukup lama untuk terhubung ditandai dengan LED yang tidak menyala karena alat harus mencari sinyal untuk terhubung ke satelit. 
Beberapa percobaan untuk melihat waktu yang dibutuh GPS untuk dapat terhubung dengan satelit.

Table. 1 Waktu Hasil Respon GPS

\begin{tabular}{|c|c|}
\hline $\begin{array}{c}\text { Percobaan } \\
\text { ke- }\end{array}$ & Waktu yang dibutuhkan \\
\hline 1 & 10 detik \\
\hline 2 & 12 detik \\
\hline 3 & 7 detik \\
\hline 4 & 9 detik \\
\hline 5 & 7 detik \\
\hline
\end{tabular}

2) Pengukuran Akurasi GPS

Table. 2 hasil uji akurasi GPS

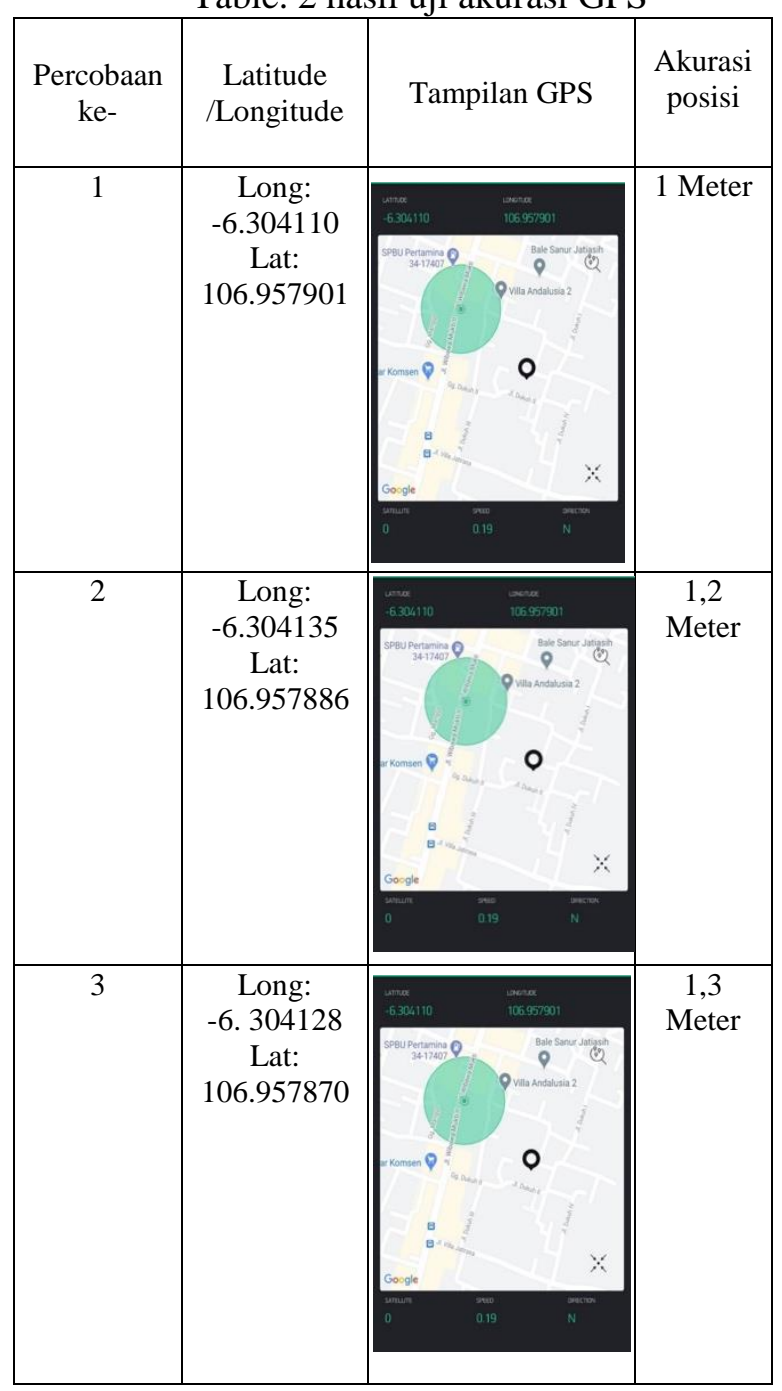

Pengujian akurasi posisi dilakukan untuk mengetahui penyimpangan dari posisi modul GPS yang terpasang pada sepeda motor dengan tampilan pada blynk. Kita ketahui pada datasheet penyimpangan pada GPS berkisar di jarak 2,5 dari posisi realtime, dan saat pengujian menunjukkan tingkat akurasi yang lebih baik sehingga titik koordinat mengarahkan map ke sepeda motor tidak terlalu jauh.

\section{KESIMPULAN DAN SARAN}

\section{A. Kesimpulan}

Berdasarkan

penelitian

pada Implementasi Modul GPS UBLOX 6M dalam rancang bangun sistem keamanan motor berbasis Internet Of Things ini memiliki beberapa kesimpulan, diantaranya ialah sebagai berikut;

1. Dengan menggunakan sistem keamanan sepeda motor berbasis aplikasi android ini dapat memudahkan dalam mengetahui posisi kendaraan yang telah dicuri.

2. Sistem dapat bekerja dengan baik dalam mengendalikan relay yaitu dapat memutus dan menghubungkan aliran listrik pada mesin motor dengan control jarak jauh menggunakan aplikasi android (Blynk)

\section{B. Saran}

Penelitian ini masih jauh dari kesempuranaan. Untuk menciptakan sebuah sistem yang baik, perlu adanya kajian lebih lanjut agar dapat mengembangkan penelitian ini ke tahap yang lebih kompleks. Adapun saran yang terdapat dalam penelitian ini ialah sebagai berikut.

1. Sistem keamanan untuk kendaraan dengan GPS dan dipantau lansung smartphone ini diharapkan nantinya dapat dikembangkan menjadi sistem yang tidak hanya untuk melacak lokasi kendaraan tetapi juga dapat digunakan untuk mengontrol sistem.

2. Untuk pengembangan selanjutnya mencari GPS yang mampu menangkap sinyal di tempat tertutup ataupun tempat terbuka dengan memanfaatkan berbagai situasi dan kondisi lingkungan saat ini.

3. Untuk pengembangan lebih lanjut diharapkan alat ini dapat dijadikan sistem keamanan untuk kendaraan yang akan dijual umum, sehingga setiap kendaraan akan mempunyai id kendaraan masingmasing dan dapat dilacak oleh setiap pemilik kendaraan dengan smartphone. 


\section{UCAPAN TERIMA KASIH}

Saya ucapakan Terimaksih kepada Tuhan yang Maha Esa karna sampe saat ini masih diberikan kesehatan.

\section{REFERENSI}

[1] Nicodemus Rahanra, "Sistem Perbuatan Kunci Otomatis Untuk Keamanan Sepeda Motor Menggunakan Arduino Berbasis Android," Jurnal FATESKA, Vol. 2,2017.

[2] Yuliarman Saragih., Gilang Ramadhany Hakim., Hasna Aliya Roostiani., "Monitoring Design of Methods and Contents Methods in Semi Real Water Tandon by Using Arduio - based on Internet of Things, " 4 th International Conference and Workshops on Recent Advances and Innovations in Engineering, 2019.

[3] Purhendi Bayu Basuki., Unang Sunarya, S.T., M.T., Atik Novianti, S.ST., M.T., "Perancangan Sistem Keamanan Sepeda di Tempat Umum Berbasis RFID, "Jurnal Elektro Telekomunikasi Terapan, 2017.

[4] Harun Sujadi., Tri Ferga Prasetyo., Pafsi Paisal., "Pengembangan Sistem Monitoring Keamanan Sepeda Motor Berbasis Internet Of Things, "Jurnal JEnsitec, Vol. 5,2018.

[5] Husnibes Muchtar1., Bayu Firdaus., "Perancangan Sistem Keamanan Tambahan Pada Kendaraan Sepeda Motor Berbasis Aplikasi Android Dengan Menggunakan Mikrokontoler," Jurnal UMJ, 2017.

[6] Dyas Yudi Priyanggodo, "Pemanfaatan GPS sebagai Mendapatkan Pertolongan Ketika Dalam Kondisi Bahaya Dengan Algoritma Divide and Contquer Untuk
Lokasi Terdekat," Jurnal Teknik Informatika (JIKA), 2019.

[7] Johan Manurung1., Missyamsu Algusri., "Sistem Keamanan Sepeda Motor Berbasis GPS dan Android," Sigma Teknika, Vol. 2, 2019.

[8] Agatha Elisabet S., Yuliarman Saragih., Ibrahim Lammada., Anta Wijaya., Olivia Monica Aprilia., "Redesign of Application with Notification of $4 G$ Drive Test Results Cellular Network Case Study Area Converage of Universitas Singaperbangsa Karawang," 3rd International Conference on Mechanical, Electronics, Computer, and Industrial Technology (MECnIT), 2020.

[9] Agus Nurhartono., "Perancangan Sistem Keamanan Untuk Mengetahui Posisi Kendaraan yang Hilang Berbasis GPS dan Ditampilkan dengan Smartphone," Universitas Negri Yogyakarta, 2015.

[10] Hendra Nugraha Lengkong., Alicia A.E. Sinsuw, ST., MT., Arie S.M Lumenta, ST., MT., "Perancangan Penunjuk Rute Pada Kendaraan Pribadi Menggunakan Aplikasi Mobile GIS Berbasis Android Yang Terintegrasi Pada Google Maps," Ejournal Teknik Elektro dan Komputer, 2015.

[11] Muhammad Thoriq., "Rancang Bangun Sistem Keamanan Kendaraan Bermotor Berbasis Internet Of Things Dengan Modul NODEMCU V3 ESP8266," Jurnal Teknik Elektro, Vol. 09, 2020

[12] Abdul Halim Mukti Nasution., Sri Indriani., Nida Fadhilah., Chandra Arifin., Saut Parsaoran Tamba., "Pengontrolan Lampu Jarak Jauh Dengan NodeMCU Menggunakan Blynk, Jurnal TEKINKOM, Vol. 2, 2019 